\title{
A Cascaded Multilevel Inverter Using Bidirectional H-bridge Modules
}

\author{
Feel-soon Kang *and Yeun-Ho Joung*
}

\begin{abstract}
This paper presents a multilevel inverter configuration which is designed by insertion of a bidirectional switch between capacitive voltage sources and a conventional $\mathrm{H}$-bridge module. The modified inverter can produce a better sinusoidal waveform by increasing the number of output voltage levels. By serial connection of two modified $\mathrm{H}$-bridge modules, it is possible to produce 9 output voltage levels including zero. There are 24 basic switching patterns with the 9 output voltage levels. Among the patterns, we select the 2 most efficient switching patterns to get a lower switching loss and minimum $d v / d t$ stress. We then analyze characteristics of Total Harmonic Distortion (THD) of the output voltage with variation of input voltage by computer-aided simulations and experiments.
\end{abstract}

Keywords: Bidirectional switch, Inverters, Multilevel systems, Total harmonic distortion (THD), H-bridge module

\section{Introduction}

The cascaded H-bridge multilevel inverter has been researched for high voltage applications since it has advantages in number of components, high reliability, and modularity [1]-[6]. The main purpose of a multilevel inverter is the generation of a high voltage using lower voltage rating devices connected in series. Also it has the potential to get a high quality output voltage by producing multi output voltage levels. However, it increases the number of switching devices and other components, which results in an increase of complexity problems and system cost.

Many multilevel inverter configurations have been researched to get a sinusoidal-like output voltage wave with minimum circuit components [7]-[11]. In reference [7], authors have tried to increase the number of output levels by switched series/parallel DC voltage sources. However, the configuration has brought a weakness in usage of high voltage applications due to its complexity in switch control and voltage stress (same as its input voltage source).

To alleviate these problems, multilevel inverters using a cascaded transformer have been studied in [8]. In the paper, the cascaded transformers produce trinary output voltage and it improves the shape of the output voltage waveform.

\footnotetext{
* Dept. of Electronic and Control Engineering, Hanbat National

University, Korea (feelsoon@ieee.org, feelsoon@hanbat.ac.kr,

hyjoung@hanbat.ac.kr)

Received06 November 2012 ; Accepted 23 November2012
}

Reference [9] has a very similar concept with reference [8] but the configuration is suitable for high capacity applications. The multilevel inverter approach has merits in reduction of the number of switching devices and in a galvanic isolation between the source and loads by employing a cascaded transformer. However, it may decrease the power conversion efficiency, and increases volume and cost of the system due to the transformer. To decrease the number of transformers, a modified version of the cascaded-transformer based multilevel inverter has been reported in [10]. Authors in the paper have proposed two kinds of inverters according to the role. One is a level inverter, and the other is a Pulse Width Modulation (PWM) inverter. Pulse width modulated wave is added on a fundamental voltage level, which is generated by the Level inverter. The chopped wave is changed into a sinusoidal wave when load current is increased due to the filtering effect by the leakage inductance of the transformer. The presentable advantage of the method is to produce a high quality output voltage wave with a reduced number of transformers. However, it still has a drawback in power conversion loss generated by usage of the transformers. Moreover, those approaches in [8]-[10] employing low frequency transformers are inappropriate to the motor driver, which is operated by Variable Frequency (VF) control scheme due to saturation problem of the transformer.

The multilevel inverters in the references [7]-[11] have been designed with a cascaded H-bridge configuration. In general, the H-bridge configuration has an advantage in 
modularity and is a very efficient configuration to get multi output voltage level with minimum electric components. Therefore the cascaded H-bridge integrated multilevel inverter has been utilized for the decentralized power supply system of large capacity STATCOM [11] and solar power generation [12]. However, the cascaded H-bridge multilevel inverter requires multi input voltage sources to achieve multilevel output voltage [13] and insertion of input capacitors to get multi input voltage sources induces an imbalance of the input voltages [14]-[16].

We propose a modified multilevel inverter configuration to reduce the number of independent input voltage sources with minimum electric components and a maximum output voltage level. The proposed cascaded H-bridge multilevel inverter is configured by two independent DC input voltage sources, two H-bridge modules, and two bidirectional switches and it produces nine output voltage levels. There are 24 basic switching patterns with the 9 output voltage levels. Among the patterns, we select the 2 most efficient switching patterns to get lower switching loss and minimum $d v / d t$ stress. Then we analyze characteristics of Total Harmonic Distortion (THD) of the output voltage with variation of input voltage. To verify the validity of the proposed multilevel inverter, we carried out a simulation and experiments based on a prototype.

\section{Proposed Multilevel Inverter}

\subsection{General Cascaded H-bridge Multilevel Inverter}

Fig. 1 shows a circuit configuration of a general cascaded $\mathrm{H}$-bridge multilevel inverter. Each $\mathrm{H}$-bridge module has an independent DC voltage source of $E$. Every output terminal of H-bridge cells is connected in series. So the output voltage can be obtained by Eq. (1). And the number of output voltage levels is obtained by Eq. (2).

$$
\begin{aligned}
& v_{\text {out }}=\sum_{n=1}^{k} v_{n}=v_{1}+v_{2}+v_{3}+v_{4} \\
& N=2 k+1
\end{aligned}
$$

where $k$ is the number of $\mathrm{H}$-bridge cells.

In Eq. (1), $v_{n}$ can be $E, 0$, or $-E$; therefore, $v_{\text {out }}$ can produce $-4 E,-3 E,-2 E,-E, 0, E, 2 E, 3 E, 4 E$ by mixing of each output voltage. We can notice that this kind of multilevel inverter is advantageous in terms of modularity and simplicity. However, it needs 16 switches and 4 independent DC input sources to produce nine output voltage levels.

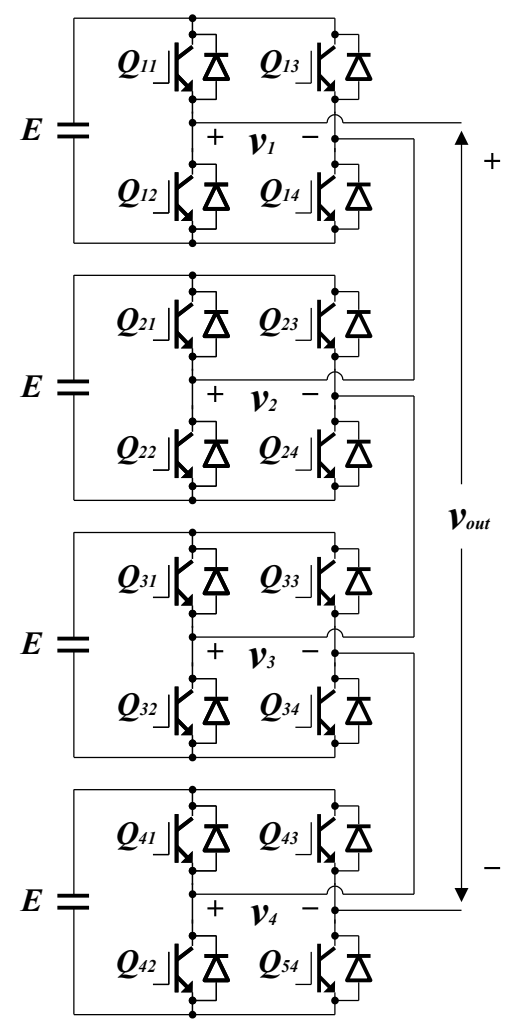

Fig. 1. Circuit configuration of a conventional cascaded Hbridge multilevel inverter to produce nine output voltage levels

\subsection{Cascaded Transformer based Multilevel Inverter}

To reduce the number of switches, a multilevel inverter using a cascaded transformer has been introduced in [8] Fig. 2 shows a multilevel inverter employing a cascaded transformer. It has a single DC voltage source, two $\mathrm{H}$ bridge cells, and two transformers. Since each secondary of the transformer is connected in series, the output voltage becomes the instantaneous sum of every secondary voltage of both transformers as given in Eq. (3). As well, the number of output voltage levels is determined by Eq. (4).

$$
v_{\text {out }}=\sum_{n=0}^{k-1} 3^{n} \cdot v_{n+1}=v_{1}+3 \cdot v_{2}
$$

$$
N=3^{k}
$$

where $k$ is the number of transformers.

In Eq. (3), $v_{n}$ can be $E, 0$, or $-E$; therefore, $v_{\text {out }}$ can produce $-4 E,-3 E,-2 E,-E, 0, E, 2 E, 3 E, 4 E$ by mixing of each secondary voltage of the transformers. 


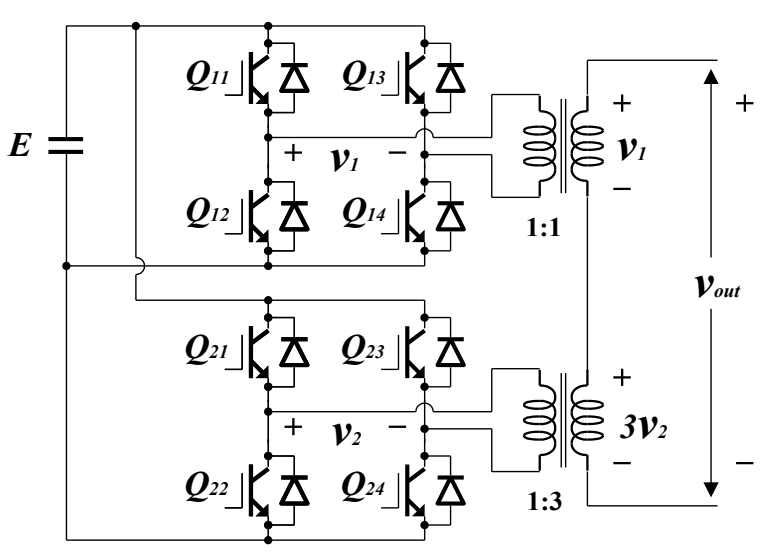

Fig. 2. Circuit configuration of a multilevel inverter having a cascaded transformer to produce nine output voltage levels

From Fig. 2, we can find that this multilevel inverter saves 8 switches and 3 DC voltage sources compared with the prior approach given in Fig. 1. It automatically achieves galvanic isolation between a source and loads by the cascaded transformer; however, it decreases the power conversion efficiency due to transformer loss, and increases total volume and cost of the system.

\subsection{Multilevel Inverter Using Bidirectional Switches}

To solve the problem of the above mentioned approaches, we present a modified multilevel inverter which has couple of bidirectional switches. One side of the switch is connected at neutral points of input voltage sources and the other is connected at neutral points of the H-bridge module as shown in Fig. 3. To generate nine output voltage levels, it needs two independent dc input voltage sources, two $\mathrm{H}$ bridge modules, and two bidirectional switches. The circuit configuration of the proposed inverter is very similar to the configuration of a serial connection of conventional 5-level inverters [17-18]. It can prevent the efficiency drop induced by transformers in the multilevel configuration of Fig. 2 . It can reduce the number of switches compared with the conventional cascaded H-bridge multilevel inverter shown in Fig. 1.

To synthesize nine output voltage levels, it employs two independent $\mathrm{dc}$ voltage sources of $2 E$ which are divided into two input sources $E$ in order to secure an additional dc voltage source of $E$. The inverter module having a bidirectional switch produces 5-levels of output voltage ($2 E,-E, 0, E, 2 E)$ by controlling of the switches. Since every output terminal of the inverter module is connected in series, the output voltage becomes the sum of the terminal voltages of each inverter.

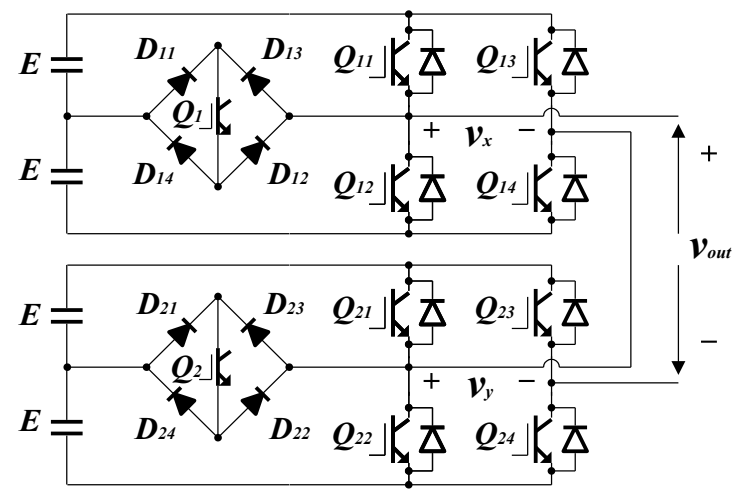

Fig. 3. Circuit configuration of the proposed multilevel inverter having bidirectional switches to produce nine output voltage levels

The switching function of an inverter can be summarized as

$$
\begin{aligned}
& \text { if }\left(Q_{n 1}, Q_{n 4}\right)=\text { on then } S F_{n}=2 \\
& \text { if }\left(Q_{n}, Q_{n 4}\right)=\text { on then } S F_{n}=1 \\
& \text { if }\left(Q_{n 1}, Q_{n 3}\right) \text { or }\left(Q_{n 2}, Q_{n 4}\right)=\text { on then } S F_{n}=0 \\
& \text { if }\left(Q_{n}, Q_{n 3}\right)=\text { on then } S F_{n}=-1 \\
& \text { if }\left(Q_{n 2}, Q_{n 3}\right)=\text { on then } S F_{n}=-2
\end{aligned}
$$

For generation of nine levels in an output voltage wave, we consider 24 switching patterns which are obtained by mixing the switching functions $\left(S F_{n}\right)$ as listed in Table 1 . It shows switching functions for generating positive output

\begin{tabular}{|c|c|c|c|c|c|}
\hline \multirow{2}{*}{$\begin{array}{l}\text { No. of output } \\
\text { levels }\end{array}$} & \multicolumn{2}{|c|}{$\begin{array}{l}\text { Switching } \\
\text { Function }\end{array}$} & \multicolumn{2}{|c|}{$\begin{array}{l}\text { Output Voltage } \\
\text { of each inverter }\end{array}$} & \multirow{2}{*}{$\begin{array}{r}\begin{array}{r}\text { Output } \\
\text { Voltage }\end{array} \\
\boldsymbol{v}_{\text {out }}\end{array}$} \\
\hline & $\mathbf{S F}_{1}$ & $\mathrm{SF}_{2}$ & $v_{x}$ & $v_{y}$ & \\
\hline 4 & 2 & 2 & $2 \mathrm{E}$ & $2 \mathrm{E}$ & $4 E$ \\
\hline \multirow{2}{*}{3} & 2 & 1 & $2 \mathrm{E}$ & E & \multirow{2}{*}{$3 E$} \\
\hline & 1 & 2 & E & $2 \mathrm{E}$ & \\
\hline \multirow{3}{*}{2} & 1 & 1 & $\mathrm{E}$ & E & \multirow{3}{*}{$2 E$} \\
\hline & 0 & 2 & 0 & $2 \mathrm{E}$ & \\
\hline & 2 & 0 & $2 \mathrm{E}$ & 0 & \\
\hline \multirow{4}{*}{1} & 0 & 1 & 0 & E & \multirow{4}{*}{$E$} \\
\hline & 1 & 0 & $\mathrm{E}$ & 0 & \\
\hline & 2 & -1 & $2 \mathrm{E}$ & $-E$ & \\
\hline & -1 & 2 & $-E$ & $2 \mathrm{E}$ & \\
\hline 0 & 0 & 0 & 0 & 0 & 0 \\
\hline
\end{tabular}
levels. By multiplying -1 to Table 1 , we can obtain switching functions for a negative case.

Table 1. Switching function for generating 9-level output voltage 
With the switching function, the output voltage of the proposed inverter is expressed in Eq. (6). The number of output voltage levels is given by Eq. (7).

$$
\begin{aligned}
& v_{\text {out }}=\sum_{n=1}^{\infty} S F_{n} \cdot E \\
& N=4 k+1
\end{aligned}
$$

where $k$ is the number of inverter modules.

If we apply Eq. (6) for two inverter modules, $v_{\text {out }}$ can be $4 E,-3 E,-2 E,-E, 0, E, 2 E, 3 E, 4 E$ by the selecting of a proper switching pattern.

From Table 1, we can consider 24 switching patterns to generate a 9-level output voltage. Among them, 12 switching patterns are shown in Fig. 4. The remainder is in symmetry. The symmetry can be obtained by multiplying -1 to the voltages. For example, in pattern $1, v_{x}-v_{y}$ becomes $v_{\text {out }}$ at positive polarity. On the other hand, $v_{y}-v_{x}$ becomes $v_{\text {out }}$ for a negative.

Fig.4 shows output patterns of the upper and lower module. During the pattern selection, cross switching was avoided. That is, if the $v_{x}$ indicates upper module output voltage levels with a positive polarity, then $v_{y}$ should be a lower module output voltage level with a negative polarity. In the Fig. 4, switching pattern 1, 2, 10 has low switching times in a period. Other patterns have more switching times or have relatively higher $d v / d t$ variation. We exclude the patterns in analyses and experiments. In the case of pattern 10 , the power capacity on the upper module is much higher than on the lower module. This difference of power capacity on the modules can induce a gap in power capacity and lifetime in the switches. Therefore we study the switching pattern for the pattern 1 and 2 with simulation and experiment in this paper.

\section{Simulations and Experiments}

We performed computer-aided simulations for pattern 1 and 2 with the modified H-bridge multilevel inverter. The simulation was implemented by PSpice with consideration for pure resistive load. Fig. 5 shows simulation waveforms of pattern 1 and 2. It shows output voltage $\left(v_{\text {out }}\right)$, terminal voltages of the upper $\left(v_{x}\right)$ and the lower $\left(v_{y}\right)$ inverter in sequence.

We can notice that one inverter generates a fundamental output voltage, and then another inverter adds voltages on the fundamental voltage to produce stepped waves. Consequently, the final output voltage becomes the sum of the terminal voltage of $\mathrm{H}$-bridge modules. A patterning difference of patterns 1 and 2 comes from the output voltage's switching angle difference of the upper and lower module.

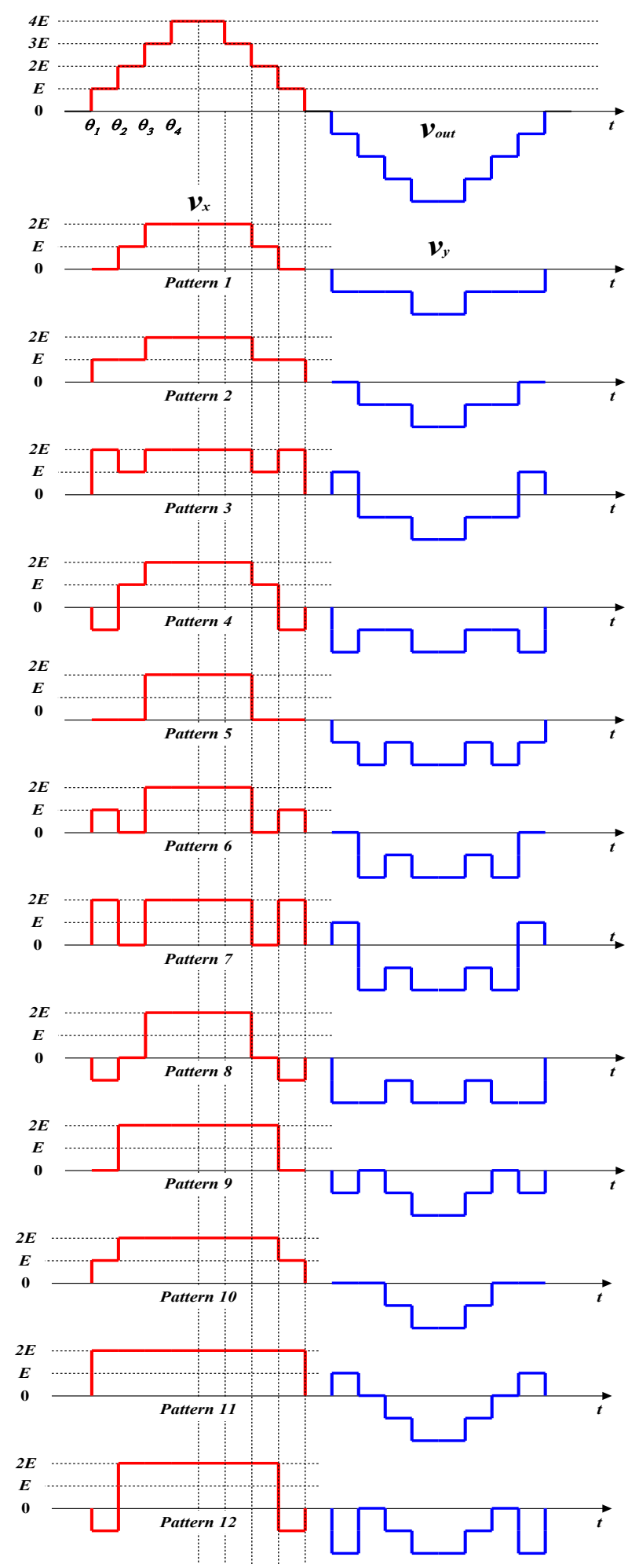

Fig. 4. Switching patterns for generating a 9-level output voltage 


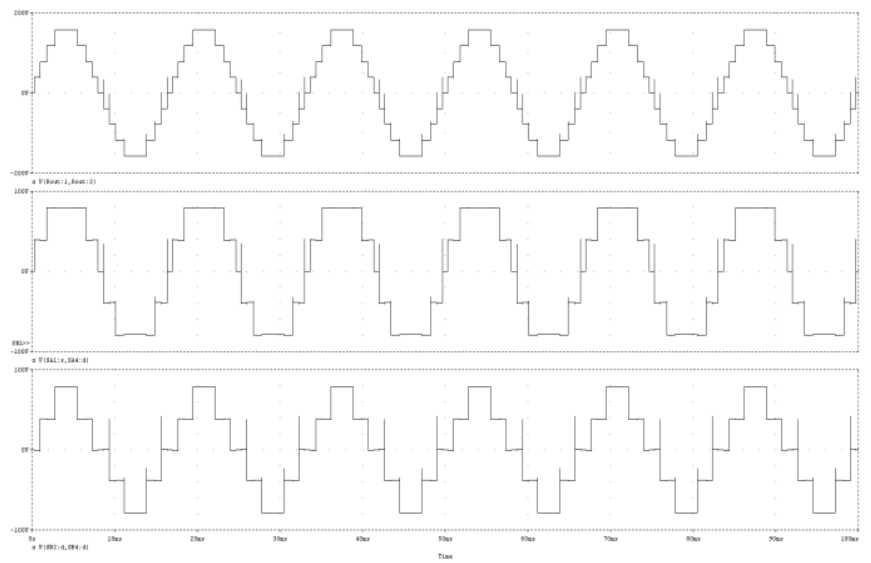

(a)

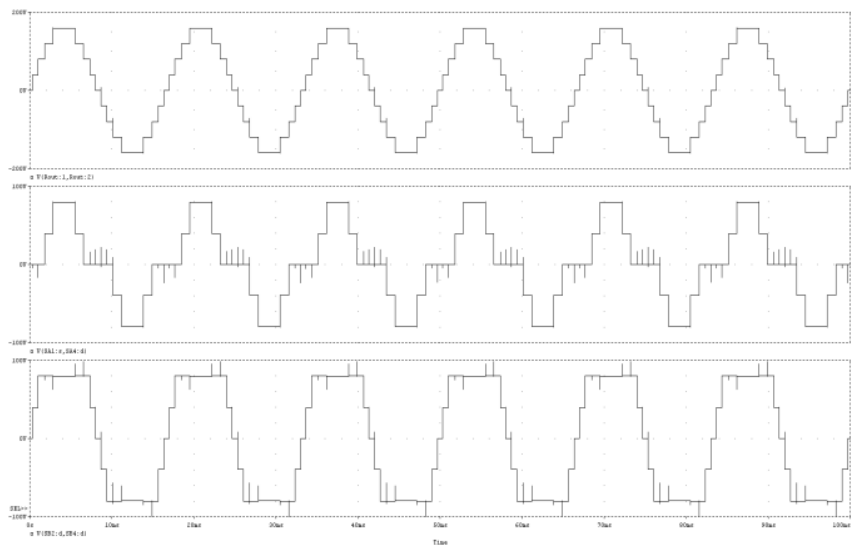

(b)

Fig. 5. Simulation waveforms of output voltage $\left(v_{\text {out }}\right)$, output voltages of the upper inverter $\left(v_{x}\right)$ and the lower inverter $\left(v_{y}\right)$, (a) Pattern 1, (b) Pattern 2

If we explain the result with energy transfer, the difference of the output voltage's area in the upper and lower modules in pattern 1 is much smaller than pattern 2 's. From Fig.5, the area of the waveform can be translated as the energy transfer from each module to the load. By simple visual comparison, we can see the area difference between upper and lower modules in pattern 1 is smaller than pattern 2. The proposed multilevel inverter requires two independent input voltage sources for the upper and lower inverter module and each input voltage source is connected with two capacitors which are in series. Therefore, there is a possibility that voltages difference on the capacitors influences the THD of the output voltages. To analyze the effect, we chose 6 cases summarized in Table 2 and executed simulations. Fig. 6 shows variations of the output voltage's THD when voltage on the upper or lower module is increased with a constant dc $160 \mathrm{~V}$ total input voltage. When the upper module voltage is higher (case1), the simulation result is shown in Fig. 6(a). With the switching pattern 1 , the THD variation of output voltage is less than $1 \%$ as input voltage is changed. But, with switching pattern 2, the THD variation of output voltage is drastically increased by as much as $18 \%$ when input voltage is changed. If we explain the result with Fig. 5, the fundamental voltage (upper module voltage in pattern 1 and lower module voltage in pattern 2) waveform is added with the counterpart modules' voltage (lower module voltage in pattern 1 and upper module voltage in pattern 2) waveform to produce output voltage waveform. In pattern 1, the fundamental and the added voltage have very similar waveforms. Therefore, the THD of the output voltage was little effected by the added voltage. However, in pattern 2, the fundamental voltage (lower module voltage) is a more similar waveform to the final waveform than the added voltage (upper module voltage). If we increase the voltage of the upper module voltage in pattern 2 , the steps between each angle on the upper level is increased. Therefore the final waveform of the output voltage in pattern 2 has a bigger distortion than pattern 1. Fig. 6(b) shows case 2 that is higher voltage on the lower module with constant total input voltage (dc 160V). The result shows that the THD variation of output voltage is almost same in case of pattern 1 and pattern 2. Even though voltage of the lower module in the pattern is increased, the final output voltage waveform is followed by the increased lower module waveform.

Table 2. Case SUMMARY: The variation of output voltage by capacitive input voltage difference

\begin{tabular}{|c|l|}
\hline Case & \multicolumn{1}{|c|}{ Condition } \\
\hline 1 & $\begin{array}{l}\text { Higher voltage on the upper module, Total input } \\
\text { voltage: DC 160 V }\end{array}$ \\
\hline 2 & $\begin{array}{l}\text { Higher voltage on the lower module, Total input } \\
\text { voltage: DC 160 V }\end{array}$ \\
\hline 3 & $\begin{array}{l}\text { Higher capacitive voltage cross the upper } \\
\text { capacitor on the upper module, Input voltage on } \\
\text { lower module: DC 80 V }\end{array}$ \\
\hline 4 & $\begin{array}{l}\text { Higher capacitive voltage cross the lower } \\
\text { capacitor on the upper module, Input voltage on } \\
\text { lower module: DC 80 V }\end{array}$ \\
\hline 5 & $\begin{array}{l}\text { Higher capacitive voltage cross the upper } \\
\text { capacitor on the lower module, Input voltage on } \\
\text { upper module: DC 80 V }\end{array}$ \\
\hline 6 & $\begin{array}{l}\text { Higher capacitive voltage cross the lower } \\
\text { capacitor on the lower module, Input voltage on } \\
\text { upper module: DC 80 V }\end{array}$ \\
\hline
\end{tabular}




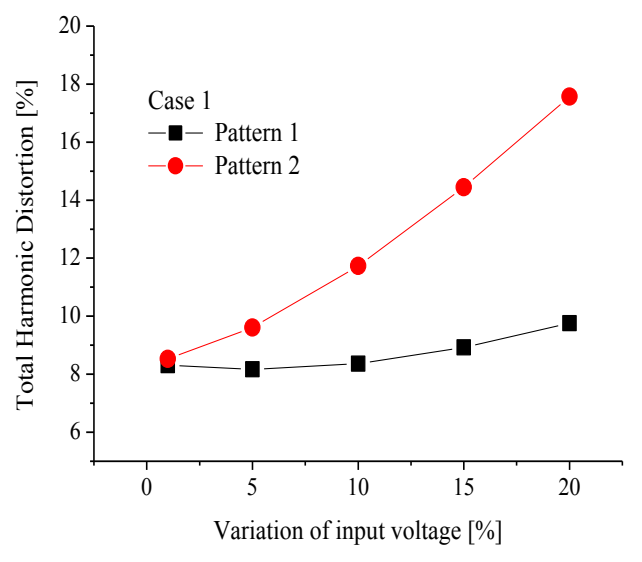

(a)

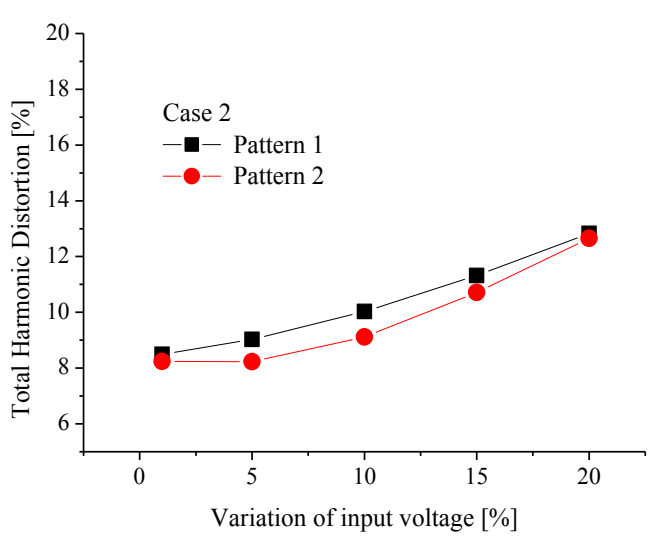

(b)

Fig. 6. Output voltage's THD variation as capacitive input voltage is varied. (a) Case 1, (b) Case 2

Fig. 7 describes simulation results of case 3 to case 6 in Table 2. As described in the previous result, when variation of the total input voltage is relatively big, pattern 1 has better performance in the THD variation of output voltage. However, with relatively less variation of input voltage in case $3 \sim 6$, the pattern 2 has better performance in the THD variation of output voltage. From Fig. 5, lower module of pattern 2 is the dominant waveform in production of the final output voltage waveform. With the condition of case $3 \sim 6$, the input voltage variation is relatively smaller than case 1 and 2 . That is, the input voltage variation has little influence on the final output voltage waveform. Therefore, the output voltage waveform in pattern 2 has a similarity to the voltage waveform in the lower module which is dominant. But in pattern 1, the waveforms of the lower and upper have very similar shape.

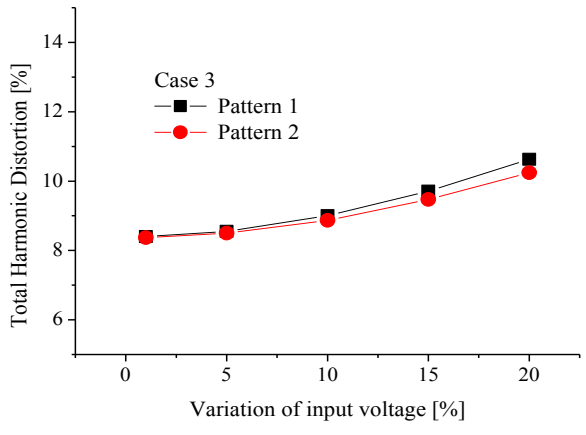

(a)

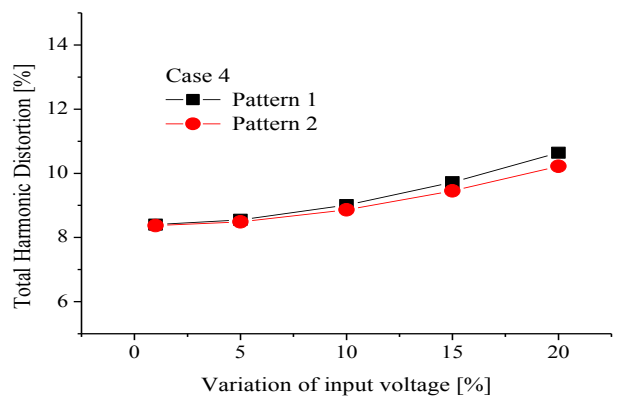

(b)

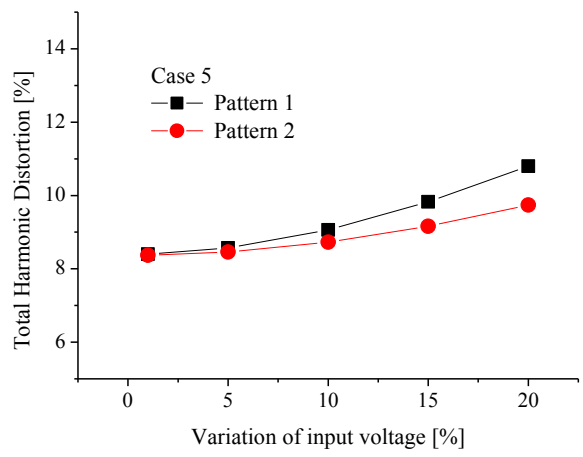

(c)

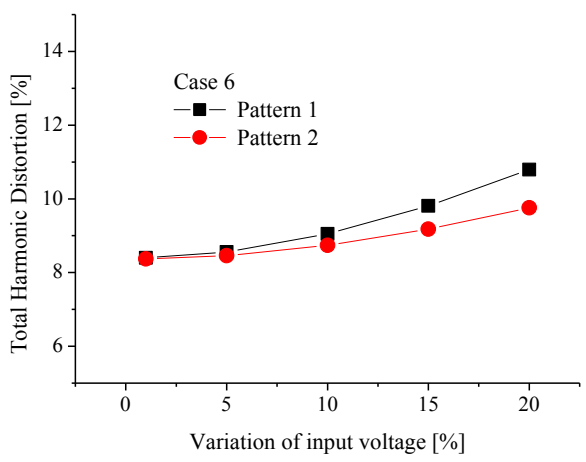

(d)

Fig. 7. Output voltage's THD variation as capacitive input voltage is varied, (a) Case 3, (b) Case 4, (c) Case 5, (d) Case 6 


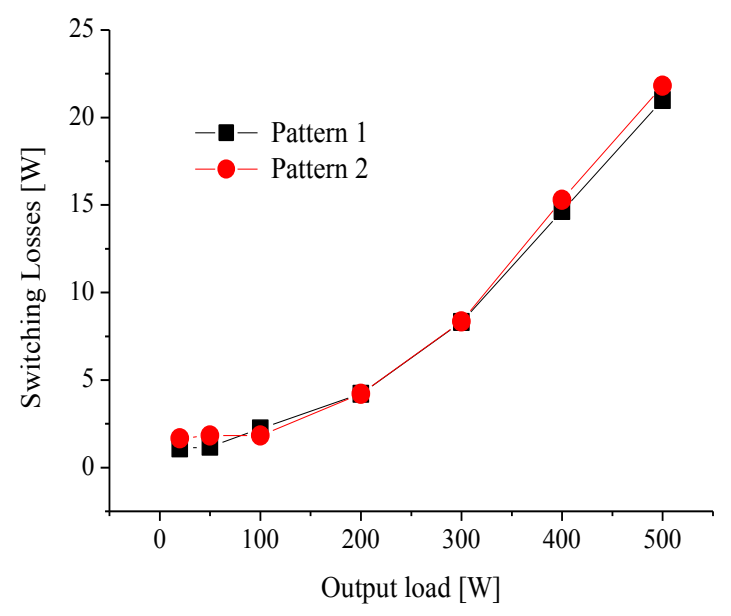

Fig. 8. Switching loss comparison of pattern 1 and 2 with output load variation

Fig. 8 describes the switching loss of pattern 1 and 2 with output load variation. The result shows that there is very similar switching loss, but it seems that the pattern 1 has a little better performance than pattern 2 . This tiny difference seems to be generated by a difference of switching angle which can produce changing of the current value. From the above simulation results, switching pattern 1 is appropriate to the proposed circuit configuration because of its better performance in switching loss, and in THD characteristics of output voltage. Also the switches in pattern 1 can have longer life times since the applied power capacity on the switches has little difference. That is, the difference in pattern 1 is smaller than the one of the pattern 2 .

Based on the simulation results, the proposed multilevel inverter was tested by a prototype. As a controller, AVR MEGA 128 was used. Fig. 9 shows experimental waveforms of pattern 1 and 2 . It includes a reference voltage, output voltage $\left(v_{\text {out }}\right)$, terminal voltages of the upper $\left(v_{x}\right)$ and the lower $\left(v_{y}\right)$ inverter in sequence. The output voltage has nine levels including a zero level. Although it is close to a sinusoidal wave, it has some lower order harmonics. So it should be improved by more H-bridge modules or output filter to obtain high quality output voltages.

Fig. 10 is an efficiency comparison of two switching patterns when it is applied for the proposed inverter with variation of output load from 0 to $500 \mathrm{~W}$. The simulation and experimental results show that the switching pattern 1 has a little better performance in the efficiency.

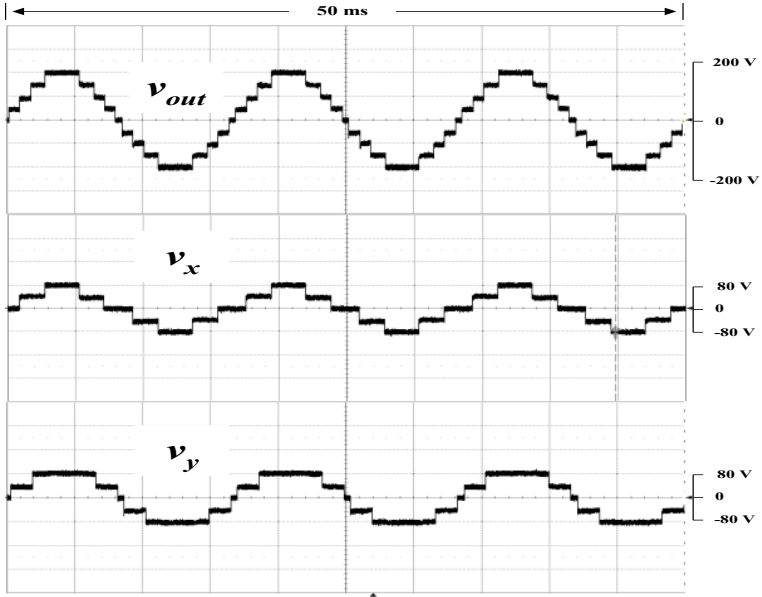

(a)

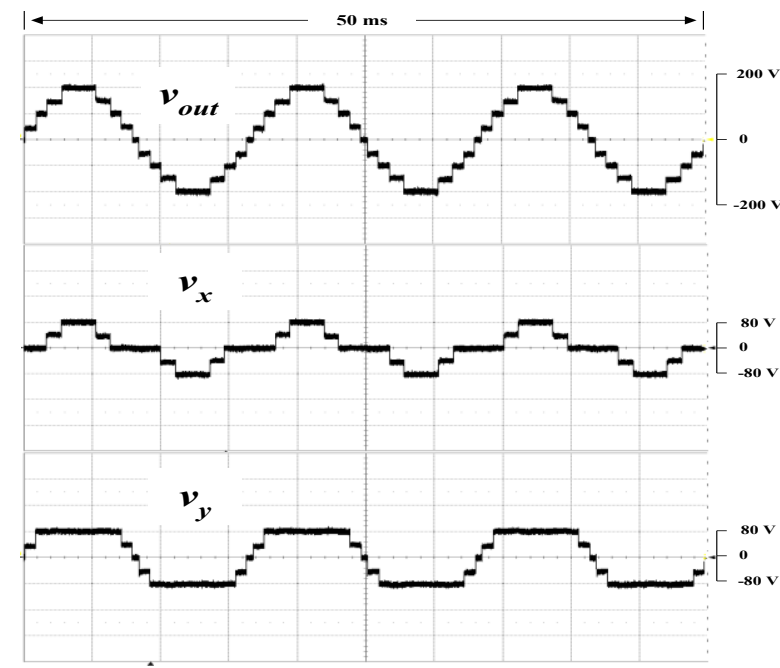

(b)

Fig. 9. Experimental waveforms of output voltage $\left(v_{\text {out }}\right)$, terminal voltages of the upper inverter $\left(v_{x}\right)$ and the lower inverter $\left(v_{y}\right)$, (a) pattern 1 , (b) pattern 2

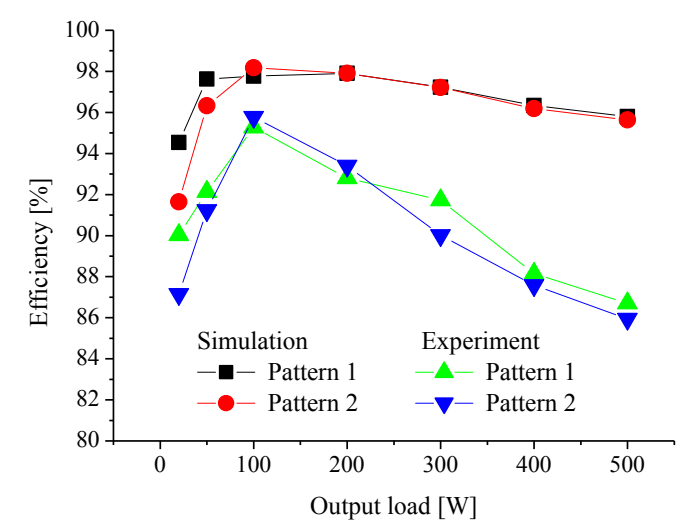

Fig. 10. Efficiency comparison with the switching patterns 
With the simulation and experiment result, we can have short time to look back on complexity of the conventional multilevel inverters, i.e., diode-clamped, flying capacitor, cascaded H-bridge, and cascaded transformer based multilevel inverters. In the case of diode-clamped, a large number of clamping diodes are a severe drawback. And a lot of balancing capacitors is a disadvantage of the flying capacitor method. Among them, the isolated cascaded Hbridge multilevel inverter looks very effective to synthesize output voltage levels. It only needs a single dc input source. However, it shows low efficiency because of adopting a cascaded transformer. And it will be suffered from large size and heavy weight. Moreover, this method is not desirable for the motor drives employing VF control scheme because of the saturation of the transformer.

From the comparison, it is clear that the most outstanding advantage of the proposed multilevel inverter scheme is the elimination of the transformer in the main power stage. However, each cell of the proposed multilevel inverter requires its own isolated power supply. The provision of these isolated supplies is the main limitation in the power electronic circuit design. So the proposed multilevel inverter is suitable for photovoltaic power generating systems equipped with distributed power sources.

\section{Conclusion}

We proposed a cascaded H-bridge multilevel inverter using bidirectional switches to increase the number of output voltage levels with minimum devices. The circuit configuration is simple and easy to control. The operational principle and key waveforms are illustrated and analyzed. Also, we have selected two kinds of switching patterns among 24 patterns, which can produce a 9-level output voltage.

From simulations and experiments, we claims that the proposed multilevel inverter is

(1) Economically sound for produinge multilevel outputs by using bidirectional switches,

(2) Easy for increasing the output voltage levels and output power owing to its modularity characteristic

(3) Efficient in the power management with switching pattern 1 due to its lower THD variation, longer switch lifetime and lower switching loss.

The proposed multilevel inverters can be utilized in solar power generation, which has merits as an independent voltage source.

\section{Acknowledgement}

This research was supported by Basic Science Research Program through the National Research Foundation of Korea (NRF) funded by the Ministry of Education, Science and Technology (No. 2010-0009504).

\section{References}

[1] M. Malinowski, K. Gopakumar, J. Rodriguez, and M. A. Pérez, "A Survey on cascaded multilevel inverters," IEEE Trans. Ind. Electron., vol. 57, no. 7, pp. 2197-2206, July 2010.

[2] H. Abu-Rub, J. Holtz, J. Rodriguez, and Ge Baoming, "Medium-voltage multilevel converters state of the art, challenges, and requirements in industrial applications," IEEE Trans. Ind. Electron., vol. 57, no. 8, pp. 2581-2596, Aug. 2010.

[3] J. Rodriguez, J.-S. Lai, and F. Z. Peng, "Multilevel inverters: A survey of topologies, controls, and applications," IEEE Trans. Ind. Electron., vol. 49, no. 4, pp. 724-738, Aug. 2002.

[4] L. G. Franquelo, J. L. Rodriguez, J. Leon, S. Kouro, R. Portillo, and M. A. Prats, "The age of multilevel converters arrives," IEEE Ind. Electron. Mag., vol. 2, no. 2, pp. 28-39, Jun. 2008.

[5] J.-S. Lai and F. Z. Peng, "Multilevel converters-A new breed of power converters," IEEE Trans. Ind. Appl., vol. 32, no. 3, pp. 509-517, May 1996.

[6] L. M. Tolbert, F. Z. Peng, and T. G. Habetler, "Multilevel converters for large electric drives," IEEE Trans. Ind. Appl., vol. 35, no. 1, pp. 36-44, Jan./Feb. 1999.

[7] Y. Hinago and H. Koizumi, "A single-phase multilevel inverter using switched series/parallel dc voltage sources," IEEE Trans. Ind. Electron., vol. 57, no. 8, pp. 2643-2650, Aug. 2010.

[8] F. S. Kang, S. J. Park, M. H. Lee, and C. U. Kim, "An efficient multilevel synthesis approach and its application to a 27-level inverter," IEEE Trans. Ind. Electron., vol. 52, no. 6, pp. 1600-1606, 2005.

[9] S. G. Song, F. S. Kang, and S. J. Park, "Cascaded multilevel inverter employing three-phase transformers and single $\mathrm{dc}$ input," IEEE Trans. Ind. Electron ., vol. 56, no. 6, pp. 2005 2014 , June 2009.

[10] F. S. Kang, S. J. Park, S. E. Cho, C. U. Kim, and T. Ise, "Multilevel PWM inverters suitable for the use of stand-alone photovoltaic power systems," IEEE Trans. Energy Conv., vol. 20, no. 4, pp. 906-915, 2005.

[11] Y. Liu, A. Q. Huang, W. Song, S. Bhattacharya, and G. Tan, "Small-signal model-based control strategy for balancing individual dc capacitor voltages in cascade multilevel inverter-based STATCOM," IEEE Trans. Ind. Electron ., vol. 56, no. 6, pp. 2259-2269, June 2009.

[12] E. Villanueva, P. Correa, J. Rodríguez, and M. Pacas, "Control of a single-phase cascaded H-bridge multilevel inverter for grid-connected photovoltaic systems," IEEE Trans. Ind. Electron ., vol. 56, no. 11, pp. 4399- 4406, Nov. 2009. 
[13] D. A. Ruiz-Caballero, R. M. Ramos-Astudillo, S. A. Mussa, and M. L. Heldwein, "Symmetrical hybrid multilevel dc-ac converters with reduced number of insulated dc supplies," IEEE Trans. Ind. Electron ., vol. 57, no. 7, pp. 2307-2314, July 2010.

[14] P. Cortés, A. Wilson, S. Kouro, J. Rodriguez, and H. Abu-Rub, "Model Predictive Control of Multilevel Cascaded H-Bridge Inverters," IEEE Trans. Ind. Electron ., vol. 57, no. 8, pp. 2691-2699, Aug. 2010.

[15] Y. Liu, H. Hong, and A. Q. Huang, "Real-time calculation of switching angles minimizing THD for multilevel inverters with step modulation," IEEE Trans. Ind. Electron., vol. 56, no. 2, pp. 285-293, Feb. 2009.

[16] J. Sun, S. Beineke, and H. Grotstollen, "Optimal PWM based on realtime solution of harmonic elimination equations," IEEE Trans. Power Electron., vol. 11, no. 4, pp. 612-621, Jul 1996.

[17] S. J. Park, F. S. Kang, M. H. Lee, and C. U. Kim, "A new single-phase five-level PWM inverter employing a deadbeat control scheme," IEEE Trans. Power Electron., vol. 18, no. 18, pp. 831-843, May 2003.

[18] N. A. Rahim, and J. Selvaraj, "Multistring five-level inverter with novel PWM control scheme for PV application," IEEE Trans. Ind. Electron., vol. 57, no. 6, pp. 2111-2123, June 2010 .

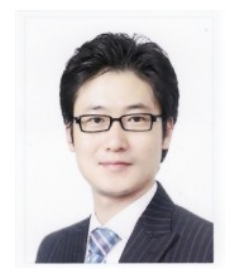

Feel-soon Kang received M.S. and Ph.D. degrees from Pusan National University, Busan, Korea in 2000 and 2003, respectively. From 2003 to 2004, he was with the Department of Electrical Engineering, Osaka University, Osaka, Japan as a Post-doctoral Fellow. Since 2004, he has been with the Department of Electronics and Control Engineering, Hanbat National University, Daejeon, Korea as an associate professor. From 2012 to 2013, he is a visiting professor in the Department of Electrical and Computer Engineering, Colorado State University. His research activities are in the area of power electronics including design and control of power converters for electric vehicles, and multilevel inverters for photovoltaic power generating systems. He received an Award from IEEE Industrial Electronics Society and the Best Presentation Prize at IEEE IECON'01 be held in Denver, Colorado USA in 2001. He was honored an Academic Award from Graduate School of Pusan National University and Hanbat National University in 2003 and 2005, respectively. And he also received several Best Paper Awards from The Korean Institute of Power Electronics (KIPE), The Korean Institute of Electrical Engineers (KIEE), and The Korea Institute of Maritime Information and Communication Science (KIMICS). He served as Cochairs and secretary for ICEMS 2010, MAGLEV 2011,
VPPC 2012, and other domestic and international conferences. Dr. Kang is an Associate Editor in the IEEE Transactions on Industrial Electronics and JICEMS.

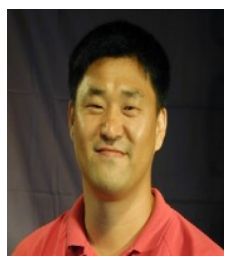

Yeun-Ho Joung received the B.S. and M.S.E.E. degree from Sung-Kyun-Kwan University, Seoul, Korea in 1995 and 1997, respectively and the Ph.D. degree in electrical and computer engineering at Georgia Institute of Technology, Atlanta, in 2003. He was with CardioMEMS, INC., from 2005 to 2010, in research and development of implantable wireless medical sensor. From 2010, he joined the faculty of Electronics and control engineering of Hanbat National University, Korea. Currently he is an assistant professor of the department.

His research interests are in the field of micromachining and in microsensor and microactuator fabrication that is compatible with the IC fabrication. Other interests include medical device with microfabrication, electronic packaging, micro sensor with piezoelectric materials, and nano materials. 